\title{
Game analysis of Behaviors among Food Safety Governance subjects
}

\author{
Lisha Song ${ }^{1, \mathrm{a}}$, Qinghua Wang ${ }^{\mathrm{b}}$, Hongyang Shi ${ }^{*}$ \\ ${ }^{1}$ Jiangxi University of Traditional Chinese Medicine, School of Economics and Management, Nanchang City, Jiangxi Province, China
}

\begin{abstract}
Effective governance is the fundamental guarantee for effective food safety governance. Food safety governance involves many stakeholders and complex interest conflicts. Effective coordination of the interests and behaviors of all parties is the key to improving governance effectiveness. One of the main dilemmas of food safety governance is information asymmetry. On this basis, this paper discusses the interest relationships and behaviors of the government, enterprises, and the public in the process of food safety governance, and constructs a behavioral game analysis between the central government and local governments and between the government, enterprises, and the public. The results show that the food safety governance is the most effective when the objectives and behaviors of governance subjects are consistent and compatible. The higher the cost of central government governance is, the more proactive local governments are in governance, the better the enterprise self-restrain and self-govern, the greater the enthusiasm of the public to participate in governance is, the more effective the food safety governance.
\end{abstract}

\section{Introduction}

Food problems have plagued the people for a long time, and safe and secure food is the foundation of human survival and development. It plays a decisive role in maintaining normal life and promoting social progress. How to alleviate the contradiction between the people's growing need for a better life and the unbalanced and insufficient food safety supply is worth thinking about. The national "Thirteenth Five-Year Plan" proposes to fully implement the food safety strategy and achieve a fundamental improvement in food safety issues to ensure that the people eat healthy and eat at ease. In May 2019, the Central Committee of the Communist Party of China and the State Council issued the "Opinions on Deepening Reform and Strengthening Food Safety Work", which show that food safety is related to the health and life safety of the people and the future of the Chinese nation. The focus of clarifying the medium and long-term goals is to promote the modernization of the national governance system and governance capabilities in the field of food safety.

Governance theory emphasizes a pluralistic, democratic, cooperative, and non-ideological public administration 1. The effective way to solve public problems is to rely on extensive cooperation between the government, non-governmental organizations and individuals $^{2}$. Most ${ }^{3-6}$ scholars' studies have shown that in the field of food safety governance, a single market mechanism or government mechanism cannot effectively solve food safety issues. It should be governed by multiple entities including the government, enterprises, and the public to guide enterprises to supervise independently, encourage social participation, make full use of internal and external resources of the government, reduce administrative costs, and improve governance efficiency. Linhai $\mathrm{Wu}^{7}$ believed that the government, society, market and other diverse governance entities form a benign interactive operating mechanism based on their basic functions and coordination, integration and trust. Based on the types of risks and risk hazards, a multi-level combination of governance methods is formed to form a food safety governance pattern with multiple co-governance. On the level of food safety governance, although China has built a sound food safety system, there are still problems such as information asymmetry and uncoordinated governance bodies in practice ${ }^{8}$. Fuying Ren ${ }^{9}$ stated that food safety governance is the government (Inter-government at lower levels, government departments at the same level, etc.), between enterprise and society three work on the same food problems, However, the confusion of powers and responsibilities of supervisory entities, lack of cooperation spirit, relative decentralization of supervisory systems, unbalanced risk distribution, and mere formality of supervisory processes have led to poor food safety governance.

Food safety governance involves numerous stakeholders and complex conflicts of interest. Effective coordination of the actions of various subjects and balancing their interests are the key to improving governance efficiency. The prerequisite for achieving food safety governance goals is effective governance, the main bodies of food safety governance include the government (central and local), enterprises and the 
public (consumers, third-party organizations, media, etc.). Game theory is a commonly used theoretical tool in economic analysis, which helps to analyze the essence of the problem more deeply. It is essentially the study of the main body's choice of strategy behavior in the game process. This paper constructs a behavioral game model between the central and local governments, governments, enterprises, and the public, and analyzes the behaviors of food safety governance subjects, in order to provide reference opinions for food safety governance.

\section{Analysis of the relationship and behavior among governance subjects}

Since the term "stakeholder" was first mentioned by Freeman, most scholars have understood and innovated the theory, and have achieved significant research results. This theory is also applicable in the field of food safety governance. Yong Zhang ${ }^{10}$ believed that the government, manufacturers, and consumers are direct stakeholders in food safety governance, and news media, social organizations and third parties are indirect stakeholders; Yanli Chen ${ }^{11}$ believed that the direct stakeholders of food safety governance are consumers, and the indirect stakeholders are the food supplier, the third sector, and the public; the balance of interests is the government. Food safety governance is a complicated and systematic social project involving multiple governance entities such as the central government, local governments, food production companies, and the public. In specific food safety governance matters, conflicts of interest and ambiguity of rights and responsibilities among various rights centers are prone to appear.

The externality of food safety issues is very strong. Objectively, the government is required to intervene, coordinate the interest relationships between various governance entities, and promote the diverse participation of food safety governance entities. The central government is the manager, coordinating the differences between local governments and governance objectives, and weighing the interests of local governments, enterprises and the public; The local government is the executor and has a geographical advantage in specific food safety governance matters. Food production companies often have multiple objectives such as economic benefits and safe production, short-term and long-term conflicts. In different periods, the two promote or inhibit each other. Food companies create social and economic benefits and are the source of food safety issues; the public is food Direct beneficiaries of security governance and important social forces. Its interest relationship is shown in Figure 1.

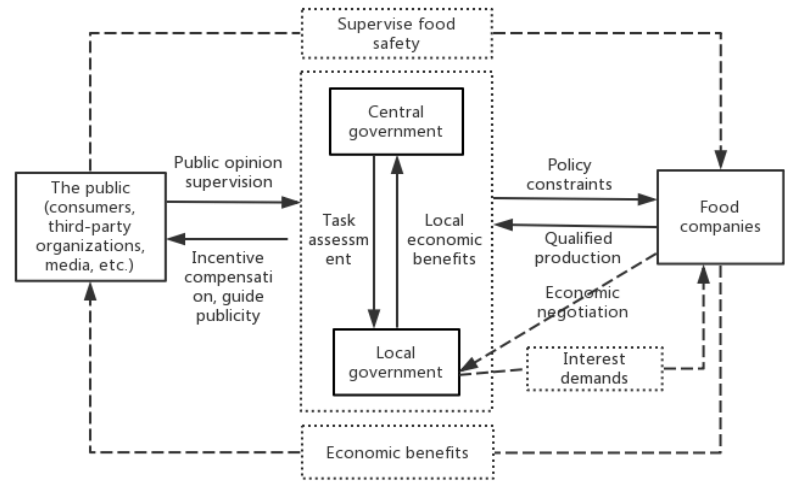

Figure 1 The interest relationship diagram of governance entities

\subsection{Analysis of government behavior}

The core of food safety governance is the government, which controls at the macro level of governance, and at the same time guides and encourages other subjects to participate together, forming a situation of multiple cogovernance. The leaders and executors of food safety governance are the central and local governments, but the local governments have the power to control and manage important local policy resources. In the process of food safety governance, the governance goals of local and central governments may be inconsistent. When the goals are the same, information exchanges, local and central governments work together to manage food safety issues, and food safety governance is highly efficient. When the local government focuses on local economic development, the goals are contradictory and the information is not available. The central government cannot accurately measure the effect of local government food safety governance, it cannot use incentives and punishment mechanisms to restrain local governments, and the effect of food safety governance is average. Research conducted by Baoguo Sun and Yingheng Zhou 12 showed that the degree of central government's incentives to local governments directly affects the strength of local governments' implementation of centrally issued food safety governance decisions. The central government pay attention to achieving policy goals, and local governments focus on local economic development. Therefore, driven by political achievements and local economic development, local governments will have discounts in their efforts to implement food safety governance decisions.

\subsection{Behavioral analysis of food production companies}

Enterprises are the source and the first responsible person for food safety. In food safety governance, companies have complete information on food production safety, and government and public supervision is an external binding force. To solve food safety problems, it is necessary to start from the root cause. Corporate self-governance is particularly important. As far as food companies are concerned, food companies have sufficient conditions and motivations to 
use information advantages to obtain illegal benefits. There are two main points, one is consumers' judgment on food information, It is difficult for consumers to distinguish the authenticity of information such as whether the company is safe and compliant with production and whether the food is safe. This may cause some illegal companies to reduce production costs and produce illegal products driven by profits. The other is the government's judgment on the information obtained by supervising enterprises. The government mainly relies on the sampling system to monitor whether the products produced by food companies are qualified, but companies cannot accurately determine the intensity of government supervision, and it is difficult for companies to determine whether they will be spot-checked ${ }^{13}$. The essential feature of an enterprise is that capital is profitseeking. Most food companies will focus on the ratio of production costs to profits. Food companies can be divided into two types; One is a company that strictly abides by food safety production standards, accepts government and public supervision, information disclosure, legal compliance, and transparent production; another is blindly pursuing profit maximization, reducing production costs, using unsafe raw materials and other violations of laws and regulations Behavioral business ${ }^{14}$.

\subsection{Analysis of public behavior}

The public is the manager of the country and has the right to participate in the management of public affairs, which is conducive to improving the scientificity and feasibility of policies ${ }^{15}$. The last link in the food supply chain is the consumer, it is both a direct beneficiary and a direct victim of food safety incidents and it is necessary for the public to participate in food safety governance. Firstly, it helps consumers fully obtain information related to food safety and quality, guides consumers' buying behavior, reduces the marginalization of law-abiding companies, and reduces the existence of the "lemon market"; secondly, consumers are finding food safety issues or When legitimate rights and interests are infringed, actively complain and report, enhance the ability to avoid food safety incidents, and protect consumers' health rights; thirdly public as an independent force has an irreplaceable role in participating in food safety governance, and the government should inspire The enthusiasm of public participation and the function of public opinion supervision make food problems nowhere to hide, help the government to supervise the safety of the food market, effectively reduce government supervision costs and save resources; at the same time, the public also supervises the specific law enforcement process of the government food supervision department. Supervise "supervisors" and form a restraint mechanism to effectively avoid "power rent-seeking" and official corruption.

\section{Game analysis of behavior between the central government and local governments}

\subsection{Assumption variables}

(1) The local government is a rational economic man, pursuing the maximization of interests.

(2) $x$ is the behavior of the local government to manage food safety, $\alpha$ is the incentive coefficient of the central government to local governments, $\beta$ is a fixed reward from the central government to local governments.

(3) $C$ is the cost of local government governance, $C(x)$ is a function of local government governance behavior $\mathrm{X}$.

(4) $b$ is the influence of other governance entities' actions on food safety governance, which is an uncontrollable factor.

(5) $y$ is the income generated by the local government's governance of food safety, and $y=x+b$.

(6) $Y$ is the income of the central government's food safety governance, which is affected by the variable $x$ and $b$.

\subsection{Assumptions}

(1) Income $y$ is a univariate linear function of behavior $x$ and is positively correlated. Income ${ }^{y}$ increases with the increase of behavior $x$, that is $y=x+b, y^{\prime}(x)>0$, $\mathrm{y}^{\prime \prime}(x)<0$

(2) The result of food safety governance has nothing to do with uncontrollable factor $b$, It is only related to local government governance behavior $x$.

(3) Local government behavior $x$ and uncontrollable factor $b$ jointly affect local revenue $y$ and central government revenue $Y, Y$ and $y$ are both increasing concave functions of $x$.

(4) The risks of food safety issues between the central and local governments are the same, and the benefits of local governments are linear functions, that is $Y_{1}=\beta+\alpha y=\beta+\alpha(x+b)$.

\subsection{Solution}

The income of food safety governance is $y=x+b$, and the income of the central government is $Y(x, b)$. When $b$ is constant, the greater the governance behavior $x$, the greater the income, and $Y$ is a strictly increasing function of $b$.

The expected return function of the central government is:

$$
\begin{aligned}
& E\left(y-Y_{1}(\mathrm{y})\right)=E(\mathrm{y}-\beta-\alpha \times \mathrm{y}) \\
& =-\beta+E((1-\alpha) \times y) \\
& =-\beta+(1-\alpha) E(y) \\
& =-\beta+(1-\alpha) \times x
\end{aligned}
$$


The expected return function of the government is:

$$
\begin{aligned}
& E\left(Y_{1}-C(x)\right)=E\left(Y_{1}\right)-C(x) \\
& =E(\beta+\alpha y)-C(x) \\
& =\beta+\alpha E(y)-C(x)
\end{aligned}
$$

When the local government expects the largest profit and is the optimal solution, the first-order derivative is zero.

$$
\begin{aligned}
& \frac{E^{\prime}\left(Y_{1}-C(x)\right)}{\mathrm{d}^{\prime}(x)}=(\beta+\alpha E(\mathrm{y})-C(a))^{\prime}=0 \\
& (\beta+\alpha E(\mathrm{y})-C(x))^{\prime}=0 \\
& \alpha(x+b)^{\prime}=C^{\prime}(x) \\
& \alpha=C^{\prime}(x)
\end{aligned}
$$

The results have three meanings: First, when the marginal benefit of local government governance equals the marginal cost of governance behavior, local government food safety governance efficiency is the highest; Second, when the marginal benefit $\alpha$ of the local government's food safety governance is less than the marginal cost $C^{\prime}(x)$, the local government may tend to reduce the governance efforts, and the efficiency of food safety governance at this time is low; Third, when the marginal benefit $\alpha$ of local government governance is greater than the marginal cost $C^{\prime}(x)$, local governments will tend to increase food safety governance, and food safety governance is more effective.

\section{Game analysis of behavior among the government, enterprises and the public}

\subsection{Hypothetical variables}

(1) The governing body is a rational economic man, pursuing the maximization of interests.

(2) $x$ is the behavior of the government, enterprises, and the public to participate in food safety governance.

(3) The cost consumed by each entity of $C$ in governance activities, $C_{1}(x)$ is the cost invested by the government, $C_{2}(x)$ is the cost invested by the enterprise, and $C_{3}(x)$ is the cost invested by the public.

(4) $\theta_{1}$ and $\theta_{2}$ are government and public rewards for enterprises, and $\alpha_{1}$ and $\alpha_{2}$ are government and public punishments for enterprises.

(5) The income of E food safety governance is affected by variable $x$.

\subsection{Assumptions}

(1) Revenue $Y$ is a univariate linear function of behavior $x$, which is positively correlated, and revenue increases with the increase of behavior, $Y^{\prime}(x)>0$, $Y^{\prime \prime}(x)<0$.

(2) $C_{1}(x), C_{2}(x)$ and $C_{3}(x)$ are the costs invested by the government, enterprises and the public, respectively. The cost increases with the increase of governance behavior, $C^{\prime}(x)>0$.
(3) The probability of a non-erupt food safety crisis event is $P$, and it is related to the participation of each entity in governance. The coefficient $\beta$ is determined by the size of each entity's efforts to participate in food safety governance. $P=\beta x, P \in(0,1)$.

(4) Variable $e$ refers to the benefits obtained by the government (such as social stability, government credibility, etc.), and $e_{1}$ refers to the benefits obtained by the public (such as food safety, normal rights protection, etc.)

\subsection{Solution}

The risks of food safety outbreaks are the same for the government, enterprises, and the public. The benefits of governance entities are linear functions of governance results, which are $Y_{1}, Y_{2}$, and $Y_{3}$ respectively. The specific benefits are shown in Table 1 below.

Table 1 Food safety governance income statement

\begin{tabular}{|c|c|c|c|c|}
\hline $\begin{array}{c}\text { Probability } \\
\text { of no } \\
\text { accident }\end{array}$ & $P$ & $e$ & $\theta_{1}+\theta_{2}$ & $e_{1}$ \\
\hline $\begin{array}{c}\text { Probability } \\
\text { of accident }\end{array}$ & $1-P$ & $-e+\alpha_{1}$ & $-\alpha_{1}-\alpha_{2}$ & $-e_{1}$ \\
\hline
\end{tabular}

It can be seen from Table 1 that when a food safety accident occurs, the benefits of governance entities are negative, and the behavior of each entity in the food safety governance process is inefficient. Food safety incidents are probabilistic events, and the probability cannot be zero. Once a food safety problem occurs, the loss can only be stopped in time, but this kind of governance is costly, inefficient, and undesirable. All governance entities need to work together to minimize the probability of food safety incidents and reduce losses.

When there is no food problem,

Government's benefit function: $Y_{1}=P e-C_{1}(x)$

Business profit function: $Y_{2}=P\left(\theta_{1}+\theta_{2}\right)-C_{2}(x)$

Public benefit function: $Y_{3}=P e_{1}-C_{3}(x)$

The government's expected benefit function:

$$
E\left(Y_{1}\right)=E\left(P e-C_{1}(x)\right)=E\left(\beta x e-C_{1}(x)\right)
$$

The expected benefit function of the enterprise:

$$
\begin{aligned}
& E\left(Y_{2}\right)=E\left(P\left(\theta_{1}+\theta_{2}\right)-C_{2}(x)\right) \\
& =E\left(\beta x\left(\theta_{1}+\theta_{2}\right)-C_{2}(x)\right)
\end{aligned}
$$

The expected benefit function of the public:

$$
E\left(Y_{3}\right)=E\left(P e_{1}-C_{3}(x)\right)=E\left(\beta x e_{1}-C_{3}(x)\right)
$$

For each governance entity, the optimal solution for participating in governance behavior is that the firstorder derivation of the expected benefit function is 0 , that is $E^{\prime}(Y)=0$

The solution to government governance behavior is:

$$
\begin{aligned}
& E^{\prime}\left(Y_{1}\right)=E^{\prime}\left(\beta x e-C_{1}(x)\right)=0 \\
& \left(\beta x e-C_{1}(x)\right)^{\prime}=0 \\
& e \beta=C_{1}^{\prime}(x) \\
& \beta=\frac{C_{1}^{\prime}(x)}{e}
\end{aligned}
$$


For the government, the governance effect at $x=x_{1}$ is the best, and the marginal cost benefit is the highest. $P=\beta x$, The smaller the $\beta$, the smaller the probability $P$ of food safety incidents, and the greater the government revenue .

The solution to corporate governance behavior is:

$$
\begin{aligned}
& E^{\prime}\left(Y_{2}\right)=E^{\prime}\left(\beta x\left(\theta_{1}+\theta_{2}\right)-C_{2}(x)\right)=0 \\
& {\left[\beta x\left(\theta_{1}+\theta_{2}\right)-C_{2}(x)\right]^{\prime}=0} \\
& \left(\beta x\left(\theta_{1}+\theta_{2}\right)\right)^{\prime}=C_{2}^{\prime}(x) \\
& \beta=\frac{C_{2}^{\prime}(x)}{\theta_{1}+\theta_{2}}
\end{aligned}
$$

For food companies, $x=x_{2}$ time governance has the best effect, and marginal cost benefits are the highest. The additional reward given by the government and the public to the corporate governance behavior is $\theta_{1}+\theta_{2}$, at which time the corporate gains the most.

The solution to public governance behavior is:

$$
\begin{aligned}
& \left(\beta x e_{1}-C_{3}(x)\right)^{\prime}=0 \\
& \beta e_{1}=C_{3}^{\prime}(x) \\
& \beta=\frac{C_{3}^{\prime}(x)}{e_{1}}
\end{aligned}
$$$$
E^{\prime}\left(Y_{3}\right)=E^{\prime}\left(\beta x e_{1}-C_{3}(x)\right)=0
$$

For the public, when ${ }^{x=x_{3}}$, the governance effect is the best and the marginal cost benefit is the highest. At this time, the benefit $e_{1}$ is the largest.

\section{Results \& Discussion}

In the management of food safety issues, the central and local governments will have the following two situations: when the goals are the same, the two parties work together to manage food safety issues, and the governance at this time is efficient; when the goals are contradictory, if the local government strictly controls the local food Enterprises may put local food companies at a disadvantage in the competition in the food market, and if serious, they may cause food companies to flee the local area, thereby affecting local economic development. The central government does not have a fixed standard to measure the behavior of local governments in managing food safety. It can only rely on results to make judgments on the governance behaviors of local governments. This judgment is one-sided and has errors, so local governments may tend to be lazy. Model 1 analysis found that regardless of the influence of external factors, that is, no matter how other governance subject factors change, the local government governance behavior area value is $\left(x, x_{1}\right)$, and the optimal action solution $x_{1}$ is positively correlated with the marginal benefit $\alpha$ of governance. When the marginal benefit of governance increases, local government governance is strengthened, and the governance effect is significant. Therefore, the more the central government rewards the local government, the stronger the local government's governance of food production enterprises, a virtuous circle is formed, and food safety issues are effectively governed, To achieve governance goals.

Once a food safety accident occurs, the government, enterprises, and the public will all suffer huge losses to varying degrees. The accident has already occurred and the stop loss effect is very small at this time, which is an inefficient food safety governance. In actual situations, food safety incidents that have not erupted under the iceberg cannot be ignored. How to reduce the probability of food safety incidents is the ultimate goal of governance. Although the probability of an accident cannot be zero, the probability can be controlled to a minimum. Model 2 analysis found the coefficient $\beta$ of the probability of occurrence of food safety crisis events $P$ is determined by the cost invested by the main body in governance, and the cost of governance is determined by the behavior of the governing body. When the government, enterprises, and the public want to obtain the safest food environment, they should add The large cost $C(x)$ input is an increasing concave function. When the governance body's behavior reaches $x_{1}, x_{2}$, and $x_{3}$, the marginal benefit is equal to the marginal cost of the governance behavior, and the probability of a food safety crisis event is the smallest.

\section{Suggestions}

The effective solution of food safety issues not only meets the public's needs for food safety, but also demonstrates the progress of national governance capabilities. It is impossible to achieve the goal of food safety governance by relying on a single subject. This article analyzes the game behavior of the main body participating in governance by combing the interest relationship between the main bodies, and exploring the critical value of each main body's behavior when the food safety governance is most effective. Discussing and discovering the following issues, firstly, how to make the information exchange between the subjects, which is extremely important, timely grasp the behavior of each subject to participate in governance, can reduce the loss caused by the lack of a governance link. Under the current conditions of information big data, the government has established a safe and unblocked information platform to disclose all information related to food safety, transparent food safety policy formulation process, alleviate the impact of information asymmetry, and enable food safety governance subjects There is no obstacle to the exchange of information, to increase the enthusiasm and feasibility of enterprises and the public to participate in food safety governance, to ensure the operational safety of the food market, to ensure the safety of food for the public, and to achieve diversified governance of food safety.

Secondly, it is necessary to fully consider the interests of each governance body: Food safety governance is a long-term and complex system engineering, and interest is the most important focus among them. Related stakeholders will find a balance together to meet their own interest needs, so full consideration must be given to them Governing the 
interest needs of the main body and establishing a reasonable interest coordination mechanism are the key points of the multiple governance of food safety. The government, enterprises and the public need to exchange information and clarify their own interests and needs; as the leader, the government should determine their respective rights and responsibilities, mobilize the enthusiasm of enterprises and the public to participate in governance through incentive and punishment mechanisms, and create a good social environment for food safety governance ; As a food producer, a reasonable budget for the costs and benefits invested between food safety production and its own development is extremely important. Food companies that only aim at profit will eventually be eliminated. Companies need to think rationally about long-term and short-term issues and be proactive Actively participate in food safety governance and ensure food safety; the public plays a unique role in food safety governance, is independent of government and market mechanisms, and is a fair correction of the disadvantaged position of consumers ${ }^{16}$, food safety issues The degree of risk that can be tolerated is determined by the public, and public participation in governance helps to achieve the goal of food governance.

\section{Acknowledgments}

"Food Safety Governance Pattern Evolution and Improvement Strategies-Based on the Perspective of Big Health" (No: JD16122); Jiangxi University of Traditional Chinese Medicine 1050 Talent Project Special Project, Public Health Governance and Health Industry development research.

\section{References}

1. Oxford University Press. Our Global Neighborhood: The Report of the Commission on Global Governance $[\mathrm{J}]$. George Washington Journal of International Law \& Economics, 1995(3):754-756.

2. Salamon L M. The new governance and the tools of public action: An introduction[J]. The Fordham urban law journal, 2001, 28(5):1611-1674.

3. Wang Qiushi, Shi Hongyang. Analysis on the obstacles and paths of food safety governance reform $[\mathrm{J}]$. Contemporary Finance and Economics, 2015(8): 71-78.

4. Shi Hongyang. Independent governance of food safety enterprises: target model and realization path $[\mathrm{M}]$. Beijing: Economic Management Press, 2016.

5. Wu Xiaodong. my country's food safety public governance model reform and realization path $[\mathrm{J}]$. Contemporary Finance, 2018(09): 38-47.

6. Li Jing. From "One Yuan and One Way Segmentation" to "Multiple Network Collaboration"__ The Perfect Path of China's Food Safety Supervision Mechanism[J]. Journal of Beijing
Institute of Technology (Social Science Edition), 2015(04):99 -103.

7. Wu Linhai, The Chinese Road to Food Safety Risk Management. Red Flag Manuscript, 2019(19): pp. 35-36. [

8. Food Safety Supervision. Food and Machinery, 2019. 35(8): pp. 100-103.

9. Ren Fuying, Research on the Synergy Mechanism of Food Safety Supervision Based on the Theory of Holistic Governance. Food and Machinery, 2019. 35(4): pp. 72-75, 79.

10. Zhang Yong. Research on food safety issues from the perspective of stakeholders[J]. Journal of Shanxi Agricultural University, 2011,10(10): 994-996.

11. Chen Yanli. Research on the Social Co-governance Mechanism of Food Safety[J]. Academic Exchange, 2014, 9(9): 122-126.

12. Sun Baoguo, Zhou Yingheng. Research on China's Food Safety Supervision Strategy[M]. Science Press, 2013.

13. Fu Jincun, Wang Chao. Game Analysis of Government Food Safety Regulatory DecisionsBased on the Perspective of Government and Enterprise Micro Behavior[J]. Journal of Agricultural and Forestry Economic Management, 2014, 000(003) 315-320.

14. Lei Xunping, Qiu Guanghua. Evolutionary Game Analysis of Food Industry Behavior Supervision Based on Prospect Theory[J]. System Engineering, 2016, 034(002): 82-88.

15. Niu Liangyun, Wu Linhai. Public Participation and Social Co-governance in Food Safety Supervision[J]. Gansu Social Sciences, 2017, (6): 232-237.

16. Song Qiang, Geng Hong. Holistic governanceThe new trend of China's food safety regulatory system[J]. Guizhou Social Sciences, 2012(09):87-91. 